\title{
Efektivitas teknik forward chaining dalam meningkatkan keterampilan mengenakan kemeja berkancing pada anak dengan intellectual disability taraf sedang
}

\begin{tabular}{l} 
Diah Wahyuningsih ${ }^{\text {I* }}$, Fenny \\
I,2Fakultas Psikologi, Univers \\
\hline Info Artikel \\
\hline Sejarah Artikel: \\
Diterima \\
09 September 2020 \\
Direview \\
09 September 2020 \\
Disetujui \\
29 November 2020 \\
Dipublikasikan \\
I5 Januari 202 I \\
\hline Keywords: \\
Intellectual disability, \\
perilaku berpakaian secara \\
mandiri, \\
modifikasi perilaku, \\
forward chaining
\end{tabular}

Diah Wahyuningsih"* Fenny Hartiani ${ }^{2}$

${ }^{1,2}$ Fakultas Psikologi, Universitas Indonesia

\begin{abstract}
Abstrak
Objektif: Anak-anak dengan intellectual disability menunjukkan defisit dalam fungsi adaptif. Secara khusus, anak moderate intellectual disability seringkali kesulitan melakukan tugas bantu diri dan bergantung pada orang lain. Berpakaian sendiri merupakan salah satu keterampilan bantu diri yang penting dikuasai untuk menunjang kemandirian anak. Penelitian ini bertujuan untuk menguji efektivitas teknik forward chaining untuk meningkatkan keterampilan mengenakan kemeja berkancing pada anak dengan moderate intellectual disability. Teknik forward chaining memecah keterampilan menjadi tahapan-tahapan sederhana. Dalam setiap tahapan forward chaining, anak akan diberikan prompting dan positive reinforcement.

Metode: Penelitian ini menggunakan single subject A-B design. Partisipan merupakan anak laki-laki berusia 12 tahun 4 bulan dengan moderate intellectual disability. Intervensi diberikan dalam 6 sesi dengan 30 kali percobaan.

Temuan: Terdapat perbedaan signifikan pada kemampuan mengenakan kemeja berkancing sebelum dan setelah intervensi dilakukan.

Kesimpulan: Teknik forward chaining yang melibatkan prompting dan positive reinforcement efektif dalam meningkatkan keterampilan mengenakan kemeja berkancing pada anak dengan moderate intellectual disability.
\end{abstract}

The effectiveness of forward chaining technique to increase skill of wearing buttoned shirt in child with moderate intellectual disability

Objectives: Children with intellectual disability show deficits in adaptive functioning. In particular, children with moderate intellectual disability often have difficulty in doing selfhelp skills and being dependent on others. Self-dressing is one of important self-help skill to be mastered to support children's independence. This study aimed to examine the effectiveness of forward chaining techniques to increase skill of wearing buttoned shirt in children with moderate intellectual disability. Forward chaining technique divides the skills into simpler steps. In every forward chaining steps, the child will be given prompting and positive reinforcement.

Method: This research used a single subject A-B design. Participant is a I 2 years 4 months old boy with moderate intellectual disability. The intervention was given in 6 sessions with 30 trials.

Findings: There were significant differences in the ability to wear buttoned shirts before and after the intervention.

Conclusions: The results indicate that forward chaining technique that involves prompting and positive reinforcement successfully increase the ability to wear buttoned shirt in children with moderate intellectual disabilities

*Alamat korespondensi:

[Kampus Baru UI Depok, Jawa Barat - 16424, Indonesia]

[diah.wahyuningsih@ui.ac.id', fenny.hart@gmail.com²] 


\section{Pendahuluan}

Kemampuan adaptif yang terbatas merupakan salah satu masalah yang dihadapi oleh anak dengan intellectual disability (ID). Intellectual disability didefinisikan sebagai suatu gangguan yang muncul pada masa perkembangan (sebelum usia I 8 tahun), yang meliputi defisit dalam fungsi adaptif pada domain konseptual, sosial, dan keterampilan praktis sehari-hari (APA, 2013). Intellectual disability dikategorikan ke dalam empat tingkatan, yaitu mild, moderate, severe, dan profound (APA, 20I3). Pada anak dengan tingkat keparahan moderate hingga profound pada umumnya mengalami permasalahan dalam menjalankan keterampilan adaptif yang dibutuhkan dalam kehidupan sehari-hari.

Keterampilan adaptif merupakan keterampilan praktis sehari-hari yang diperlukan untuk berfungsi dan memenuhi tuntutan lingkungan, termasuk keterampilan yang diperlukan untuk secara efektif dan mandiri merawat diri sendiri serta berinteraksi dengan orang lain (APA, 20I3). Keterampilan ini mungkin terlihat umum dikuasai oleh kebanyakan orang, namun anak yang memiliki keterbatasan intelektual, terutama dengan taraf moderate / sedang cenderung sulit untuk menguasai keterampilan tersebut. Mereka sering kali tergantung pada pengasuh untuk menyelesaikan tugas sehari-hari sederhana yang biasanya dapat dilakukan secara mandiri oleh anak-anak tipikal (Mays \& Heflin, 20I I).

Salah satu keterampilan praktis sehari-hari yang penting untuk dikuasai adalah bantu diri. Misalnya keterampilan makan, minum, menyikat gigi, dan berpakaian secara mandiri. Penguasaan keterampilan tersebut dapat menunjang kemandirian individu dengan intellectual disability (Matson \& Hong, 2019). Pencapaian keterampilan ini juga dapat mengurangi beban yang ditanggung oleh pengasuh karena waktu dan energi yang dibutuhkan untuk membantu anak melakukan tugasnya. Berkembangnyasalah satu aspek bantu diri pada anak dapat meringankan beban dan stress yang dialami oleh pengasuh (Craig et. al., 20I6). Berpakaian merupakan salah satu keterampilan bantu diri paling mendasar yang sangat penting untuk dikuasai. Dalam rutinitas sehari-hari seseorang akan mengenakan pakaian yang berfungsi untuk melindungi bagian tubuh. Apabila seorang anak tidak dapat mengenakan pakaiannya sendiri, ia akan terus-menerus dipakaikan dan bergantung kepada orang lain (Hayton, 20 I6). Dengan demikian, mengajarkan keterampilan berpakaian secara mandiri pada anak dengan intellectual disability menjadi hal yang sangat penting.

A merupakan klien di Klinik Terpadu Fakultas Psikologi Universitas Indonesia. Berdasarkan hasil pemeriksaan yang telah dilakukan, A didiagnosa dengan ID taraf sedang. Sebagai anak dengan ID taraf sedang, salah satu hambatan yang dialami oleh $A$ adalah dalam melakukan keterampilan bantu diri, khususnya berpakaian secara mandiri. Hingga di usianya saat ini, yaitu I 2 tahun 4 bulan, A belum dapat memakai baju kemeja berkancing secara mandiri dan bergantung kepada ibu. Idealnya, anak sudah dapat berpakaian secara mandiri sejak berusia 6 tahun (Marotz \& Allen, 20I3). Keberhasilan berpakaian secara mandiri juga membutuhkan keterampilan motorik halus dan kasar sebagai prasyarat (Hayton, 20 I6), pada umumnya anak ID taraf sedang juga mengalami hambatan dalam hal tersebut. Di sisi lain, A saat ini sudah memasuki usia pubertas, dan ibu memiliki berbagai pekerjaan rumah tangga yang harus diselesaikan. Ibu merasa ketidakmampuan A dalam mengenakan baju kemeja secara mandiri perlu mendapatkan perhatian khusus. Selain itu, ibu berencana untuk menyekolahkan A kembali, dimana baju berkancing merupakan pakaian wajib yang akan dipakai saat sekolah. Sejauh ini, orang tua belum mengetahui cara yang tepat untuk mengajarkan A sesuai dengan kondisi dan kemampuannya. Oleh karena itu, diperlukan adanya program intervensi yang bertujuan membantu anak berkembang lebih baik dalam kemandirian, khususnya dalam hal berpakaian. Penelitian ini bertujuan untuk melatih keterampilan mengenakan kemeja berkancing secara mandiri pada anak dengan intellectual disability taraf sedang.

Melatih keterampilan berpakaian kepada individu dengan intellectual disability telah banyak dilakukan sejak dahulu, dan program modifikasi perilaku menjadi pendekatan yang paling banyak digunakan (Matson \& Hong, 20 I 9). Secara spesifik, program ini disusun menggunakan teknik modifikasi perilaku chaining. Teknik behavioral chaining dapat digunakan untuk membentuk keterampilan yang terdiriatas urutan atau tahapan-tahapan yang kesatuannya menjadi sebuah keterampilan tertentu (Sarafino, 20I2). Teknik chaining efektif dalam mengajarkan makan, berpakaian, grooming, dan bekerja bagi 
individu dengan gangguan perkembangan (Martin \& Pear, 20I5). Chaining terbagi menjadi dua, yaitu forward chaining dan backward chaining. Dalam intervensi ini akan menggunakan forward chaining. Forward chaining merupakan teknik mengajarkan suatu rangkaian perilaku secara bertahap satu demi satu dimulai dari langkah awal hingga akhir secara berurutan (Kazdin, 20 I3; Sarafino, 20I2). Dalam forward chaining, anak diajarkan komponen pertama lalu komponen kedua, dan seterusnya (Miltenberger, 20I2). Rangkaian perilaku dimulai dari awal hingga akhir, dimana rangkaian disusun sesederhana mungkin agar memudahkan untuk dijalankan oleh anak.

Forward chaining telah dilakukan untuk mengajarkan berbagai keterampilan pada anak dengan intellectual disability. Misalnya mengajarkan keterampilan makan menggunakan sendok, menggosok gigi, dan melipat handuk serta menaruhnya ke dalam kotak (Miltenberger, 20 I2). Penelitian Mustika \& Kusumaningrum (2018) menunjukkan bahwa forward chaining efektif dalam meningkatkan kemampuan mandi secara mandiri pada anak dengan intellectual disability. Lebih spesifik, penelitian sebelumnya menunjukkan bahwa salah satu teknik yang efektif dalam meningkatkan keterampilan berpakaian pada anak dengan intellectual disability taraf sedang adalah forward chaining (Lee, Muccio, \& Osberne, 2009).

Pada forward chaining, juga terdapat pemberian prompting dan positive reinforcement untuk setiap tahapan yang dilatihkan kepada anak. Prompting diberikan untuk membantu anak dalam menguasai tahapan-tahapan perilaku. Prompting merupakan stimulus yang diberikan sebelum atau selama kemunculan perilaku, sehingga meningkatkan kemungkinan munculnya perilaku yang diharapkan (Miltenberger, 2012). Prompt yang akan diberikan antara lain video, gestural, verbal, dan physical prompts. Video prompt merupakan tayangan video seseorang yang sedang memakai kemeja berkancing, gestural prompt merupakan gerakan fisik pelaksana intervensi misalnya menunjuk, dan physical prompt berupa bimbingan secara fisik kepada anak.

Positive reinforcement yang diberikan kepada anak pada saat berhasil melakukan tahapan perilakuyang diharapkan. Reinforcement adalah proses dimana perilaku diperkuat oleh konsekuensi langsung setelah kejadian (Miltenberger, 20I2). Saat anak melakukan perilaku yang diharapkan dan memperoleh reinforcement, maka akan memperkuat dan mempertahankan perilaku tersebut (Martin \& Pear, 20 I5), dan perilaku tersebut lebih mungkin terjadi lagi di masa depan (Miltenberger, 20I2).

\section{Metode}

Variabel terikat dalam penelitian ini adalah perilaku mengenakan kemeja berkancing, sedangkan variabel bebas adalah teknik modifikasi perilaku forward chaining. Perilaku mengenakan kemeja berkancing didefinisikan sebagai perilaku yang diawali dengan mengambil kemeja dengan kondisi kancing terbuka, mengangkat kemeja dan menghadapkan bagian kemeja yang terbuka ke hadapan anak, memasukkan tangan kanan dengan posisi serong ke lubang kemeja bagian kanan, memasukkan tangan kiri ke lubang kemeja bagian kiri, menarik kemeja ke depan tubuh dengan posisi kedua ujung kemeja bagian bawah sejajar, dan memasukkan kancing ke dalam pasangan lubangnya, mulai dari atas hingga bawah sampai kemeja tertutup rapat. Metode pengumpulan data yang digunakan dalam penelitian adalah metode observasi. Berdasarkan task analysis rangkaian perilaku mengenakan kemeja berkancing, pelaksana intervensi membuat lembar observasi berupa checklist yang akan digunakan pada sesi baseline, intervensi, hingga follow-up.

Penelitian ini menggunakan metode eksperimen, single case dengan $A-B$ design (Comer \& Kendall, 20 I 3). A-B design yaitu pengambilan satu periode baseline, satu periode intervensi, dilanjutkan dengan pengukuran ulang perilaku pada saat follow-up (Kazdin, 20I 3). Penelitian ini menggunakan A-B design untuk melihat apakah penerapan forward chaining efektif untuk meningkatkan kemampuan mengenakan kemeja berkancing pada anak dengan moderate intellectual disability. Partisipan penelitian ini berjumlah satu orang $(\mathrm{N}=1)$. 
Penelitian ini terdiri dari empat fase, yaitu persiapan, baseline, intervensi, dan follow-up. Pada fase persiapan, peneliti melakukan kajian pustaka, kaji etik, analisis fungsi dari perilaku, dan asesmen reinforcement. Penelitian ini telah melalui review Komite Etik Fakultas Psikologi Universitas Indonesia. Sebelum fase baseline dilaksanakan, peneliti memberikan persetujuan / informed consent sebagai partisipan penelitian kepada ibu A. Fase baseline dilakukan untuk melihat sejauh mana kemampuan partisipan dalam mengenakan kemeja berkancing sebelum diberikan intervensi, dilaksanakan selama 2 sesi yang terdiri dari 5 kali percobaan di setiap sesi. Selanjutnya, sesi intervensi dilaksanakan selama 6 sesi dengan 5 kali percobaan di setiap sesi. Pada fase follow-up peneliti melihat sejauh mana kemampuan mengenakan kemeja berkancing bertahan tanpa adanya prompt dan reinforcement Followup dilakukan dua minggu setelah fase intervensi berakhir, terdiri dari 2 sesi dengan 5 kali percobaan di setiap sesi. Hal ini dilakukan untuk mengetahui apakah perubahan yang telah dicapai selama tahap intervensi dapat dipertahankan. Setiap sesi berlangsung selama 45-60 menit di rumah partisipan.

Penelitian ini menggunakan purposive sampling, yaitu pengambilan sampel berdasarkan penilaian peneliti mengenai siapa yang dapat memberikan informasi terbaik untuk mencapai tujuan penelitian (Kumar, 20I4). Partisipan penelitian ini merupakan klien di Klinik Terpadu Fakultas Psikologi Universitas Indonesia yang ditangani oleh peneliti. Partisipan tersebut anak laki-laki berusia I 2 tahun 4 bulan dengan inisial A. Berdasarkan hasil pemeriksaan psikologis, A didiagnosis intellectual disability dengan tingkat keparahan sedang (moderate). A memiliki riwayat keterlambatan perkembangan. Kemampuan adaptif yang dimiliki oleh A pada domain konseptual, sosial, dan praktis sehari-hari mengalami defisit. Agar dapat melakukan keterampilan pada semua domain tersebut membutuhkan pembelajaran jangka panjang dan dukungan berkelanjutan. A masih bergantung kepada orang tuanya untuk melakukan aktivitas sehari-hari salah satunya dalam berpakaian. A belum dapat mengenakan baju kemeja berkancing secara mandiri. Saat A diminta untuk memakai sendiri, ia akan merengek minta dipakaikan atau terkadang memakai baju secara terbalik serta belum dapat mengancingkan bajunya. Oleh karena itu, diperlukan penanganan untuk memakai baju kemeja pada $A$ agar melatih kemandirian $\mathrm{A}$.

Pada tahap persiapan dilakukan Functional Behavior Assessment (FBA). FBA dilakukan untuk mengidentifikasi antecedents (kondisi yang mencetus kemunculan perilaku), behavior (perilaku yang muncul), dan consequence (konsekuensi yang muncul dari munculnya perilaku). Ketiga hal tersebut digunakan sebagai landasan untuk membuat program intervensi modifikasi perilaku (Kazdin, 20 I3). Berikut merupakan gambaran analisis fungsi perilaku memakai kemeja dari $A$ :

Tabel I.

Functional Behavioral Assessment (FBA) dari perilaku A

\begin{tabular}{|c|c|c|}
\hline Antecedents & Behavior & Consequence \\
\hline $\begin{array}{l}\text { A selalu dibantu oleh ibu untuk } \\
\text { mengenakan kemeja berkancing. }\end{array}$ & A tidak mampu memakai & $\begin{array}{l}\text { A tidak dapat memakai baju } \\
\text { secara mandiri. }\end{array}$ \\
\hline $\begin{array}{l}\text { Ibu tidak mengetahui tenik yang } \\
\text { tepat untuk mengajarkan A } \\
\text { mengenakan kemeja berkancing } \\
\text { secara mandiri. }\end{array}$ & $\begin{array}{c}\text { kemeja berkancing secara } \\
\text { mendiri. }\end{array}$ & $\begin{array}{l}\text { A selalu bergantung pada ibu } \\
\text { dalam mengenakan kemeja } \\
\text { berkancing. }\end{array}$ \\
\hline
\end{tabular}

Berdasarkan tabel Functional Behavioral Assessment (FBA), diketahui terdapat beberapa hal yang mempengaruhi kemampuan A dalam mengenakan kemeja berkancing saat ini. Pertama, A selalu dibantu oleh ibunya untuk mengenakan kemeja berkancing. Kedua, ibu $A$ tidak mengetahui bagaimana cara yang tepat untuk mengajarkan $A$. Sehingga, sampai saat ini $A$ tidak dapat mengenakan kemeja berkancing secara mandiri dan selalu bergantung kepada ibunya. 
Penelitian ini menggunakan teknik modifikasi perilaku forward chaining. Sebagian besar perilaku dalam kehidupan sehari-hari dapat dipahami sebagai rantai perilaku (chain) (Kazdin, 20 I 3). Mengembangkan urutan perilaku adalah proses yang disebut chaining. Dalam teknik forward chaining, anak diajarkan komponen pertama lalu komponen kedua, dan seterusnya (Miltenberger, 20 I2). Rangkaian perilaku dimulai dari awal hingga akhir. Selain itu, diberikan positive reinforcement dan prompt untuk membantu A.

Dalam melatih kemampuan bantu diri pada anak dengan intellectual disability, perilaku yang menjadi target intervensi perlu dijabarkan ke dalam beberapa tahapan agar mudah untuk dipahami. Task analysis adalah proses menganalisis rangkaian perilaku dengan membaginya menjadi komponenkomponen stimulus-respons individu (Miltenberger, 20I2). Task analysis penting untuk dilakukan agar semua komponen rangkaian (SD dan respon) dapat diidentifikasi dengan jelas (Miltenberger, 20I2). Pelaksana intervensi membuat task analysis sesederhana mungkin berdasarkan tahapan berpakaian. Selain itu, pelaksana intervensi telah mencoba sendiri tahapan task analysis untuk memastikan sudah dan sangat sederhana untuk diaplikasikan kepada anak dengan intellectual disability.

Tahapan dalam intervensi ini adalah:

- Tahap I : Mengambil kemeja dalam kondisi kancing terbuka.

- Tahap 2 : Mengangkat kemeja dan menghadapkan bagian kemeja yang terbuka ke hadapan anak.

- Tahap 3 : Memasukkan tangan kanan dengan posisi serong ke lubang kemeja bagian kanan.

- Tahap 4 : Memasukkan tangan kiri ke lubang kemeja bagian kiri.

- Tahap 5 : Menarik kemeja ke depan tubuh dengan posisi kedua ujung kemeja bagian bawah sejajar.

- Tahap 6 : Memasukkan kancing ke dalam pasangan lubangnya, mulai dari atas hingga bawah sampai kemeja tertutup rapat.

\section{Gambar I.}

\section{Task Analysis}

$$
\mathrm{SD}_{1} \rightarrow \mathrm{R}_{1} \rightarrow \mathrm{SD}_{2} \rightarrow \mathrm{R}_{2} \rightarrow \mathrm{SD}_{3} \rightarrow \mathrm{R}_{3} \rightarrow \mathrm{SD}_{4} \rightarrow \mathrm{R}_{4} \rightarrow \mathrm{SD}_{5} \rightarrow \mathrm{R}_{5} \rightarrow \mathrm{SD}_{6} \rightarrow \mathbf{R}_{6}
$$

Behavioral chaining perilaku memakai kemeja berkancing berdasarkan pada hasil task analysis adalah:

- $\quad\left(\mathrm{SD}_{1}\right)$ Terdapat kemeja yang dilipat dengan kondisi kancing terbuka $\rightarrow\left(\mathrm{R}_{\mathrm{I}}\right)$ anak mengambil kemeja.

- $\quad\left(\mathrm{SD}_{2}\right)$ Kemeja di tangan anak $\rightarrow\left(\mathrm{R}_{2}\right)$ mengangkat kemeja dan menghadapkan bagian kemeja yang terbuka ke hadapan anak.

- $\quad\left(\mathrm{SD}_{3}\right)$ Kemeja diangkat dengan bagian terbuka menghadap ke anak $\rightarrow\left(\mathrm{R}_{3}\right)$ anak memasukkan tangan kanan dengan posisi serong ke lengan kemeja bagian kanan.

- $\quad\left(\mathrm{SD}_{4}\right)$ Tangan kanan ada di lengan kemeja kanan $\rightarrow\left(\mathrm{R}_{4}\right)$ memasukkan tangan kiri ke lubang kemeja bagian kiri.

- $\quad\left(\mathrm{SD}_{5}\right)$ Anak sudah mengenakan kemeja, namun bagian kanan dan kiri belum ditarik hingga sejajar $\rightarrow\left(R_{5}\right)$ menarik kemeja bagian kiri dan kanan ke depan tubuh dengan posisi kedua ujung kemeja bagian bawah sejajar.

- $\quad\left(\mathrm{SD}_{6}\right)$ anak sudah mengenakan kemeja dengan kondisi bagian ujung kanan dan kiri kemeja sejajar, namun belum terkancing $\rightarrow\left(R_{6}\right)$ memasukkan kancing ke dalam pasangan lubangnya satu per satu hingga seluruhnya terkancing dengan tepat.

Baseline dilakukan di rumah partisipan selama dua hari pada pagi hari pukul I 0.00- I I .00. Pelaksana intervensi meminta $A$ untuk memakai kemeja berkancing sendiri tanpa diberikan bantuan. Hasildari pelaksanaan baseline yang telah dilakukan pada sesi I dan 2 adalah kemampuan A terbatas pada penguasaan tahap pertama dari perilaku memakai baju kemeja berkancing, yaitu hanya dapat mengambil kemeja dalam kondisi kancing terbuka. Sedangkan langkah-langkah selanjutnya belum 
dapat dilakukan oleh A. Meskipun perilaku lain seperti memasukkan tangan kanan ke lubang kemeja bagian kanan dan memasukkan tangan kiri ke lubang kemeja bagian kiri sempat muncul, namun hanya terjadi satu kali dan belum dapat dilakukan secara konsisten. Dapat disimpulkan bahwa saat ini penguasaan kemampuan A dalam mengenakan kemeja berkancing terbatas pada langkah pertama, sehingga pemberian intervensi pada hari pertama akan dimulai dengan target perilaku langkah pertama dan kedua sekaligus.

\section{Tabel 2.}

\section{Rancangan Intervensi Modifikasi Perilaku}

\begin{tabular}{cll}
\hline Sesi & \multicolumn{1}{c}{ Target Perilaku } & Teknik yang digunakan \\
\hline I & Tahap I dan 2 & $\begin{array}{l}\text { Observasi; prompt (video, physical, gestural, dan } \\
\text { verbal prompt); reward (social dan consumable } \\
\text { reinforcer) }\end{array}$ \\
\hline 2 & Tahap I, 2, dan 3 & $\begin{array}{l}\text { Observasi; prompt (physical, gestural, dan verbal } \\
\text { prompt); reward (social dan consumable reinforcer) }\end{array}$ \\
\hline 3 & Tahap I, 2, 3, dan 4 & $\begin{array}{l}\text { Observasi; prompt (physical, gestural, dan verbal } \\
\text { prompt); reward (social dan consumable reinforcer) }\end{array}$ \\
\hline 4 & Tahap I, 2, 3, 4, dan 5 & $\begin{array}{l}\text { Observasi; prompt (physical, gestural, dan verbal } \\
\text { prompt); reward (social dan consumable reinforcer) }\end{array}$ \\
\hline 5 & Tahap I, 2, 3, 4, 5, dan 6 & $\begin{array}{l}\text { Observasi; prompt (physical, gestural, dan verbal } \\
\text { prompt); reward (social dan consumable reinforcer) }\end{array}$ \\
\hline 6 & Tahap I, 2, 3, 4, 5, 6 & $\begin{array}{l}\text { Observasi; prompt (physical, gestural, dan verbal } \\
\text { prompt); reward (social dan consumable reinforcer) }\end{array}$ \\
\hline
\end{tabular}

Pada setiap sesi, partisipan akan melakukan 5 kali percobaan. Indikator keberhasilan dari intervensi ini adalah ke-6 sesi berhasil dilakukan oleh partisipan, dengan persyaratan setiap sesi dinyatakan berhasil jika partisipan mampu melakukan minimal 3 dari 5 kali percobaan yang diberikan tanpa pemberian physical prompt.

Pada intervensi forward chaining ini, prompting digunakan untuk membantu $A$ dalam menguasai tahapan-tahapan perilaku memakai kemeja berkancing. Prompting yang diberikan kepada A terbagi menjadi empat, yaitu video prompting, verbal prompt, gestural prompt, dan physical prompt (Miltenberger, 20|2).

a) Video prompting: menunjukkan video berisi seseorang yang sedang melakukan rangkaian perilaku mengenakan kemeja berkancing. Video akan diperlihatkan tepat sebelum anak melakukan percobaan. Video akan ditunjukkan pada sesi pertama intervensi agar A mendapatkan contoh mengenai tugas yang akan ia jalankan.

b) Verbal Prompts: bimbingan yang diberikan kepada anak dalam bentuk instruksi secara verbal agar anak memunculkan perilaku secara tepat. Sebagai contoh "ayo ambil kemejanya", "ayo tarik bajunya kedepan".

c) Gestural Prompts: gerakan fisik atau gestur yang membantu anak memunculkan perilaku yang tepat, misalnya menunjuk ke arah yang harus diperhatikan oleh anak.

d) Physical prompt: merupakan bimbingan yang diberikan secara fisik untuk membantu memunculkan perilaku yang diharapkan secara tepat. Misalnya memegang dan mengarahkan tangan A agar dapat memasukkan tangan ke lengan kemeja. Pemberian physical prompt akan dikurangi secara bertahap. 
Pada umumnya, pelaksana intervensi akan memberikan prompt berupa physical prompt pada percobaan pertama, kedua atau pada saat anak terlihat kesulitan. Pada saat partisipan dapat melakukan langkah yang diminta hanya dengan pemberian verbal atau gestural prompt, maka hanya akan diberikan verbal atau gestural prompt saja tanpa physical prompt.

Dalam intervensi forward chaining ini, anak akan diberikan positive reinforcement ketika mampu melakukan tahapan perilaku yang diharapkan. Pelaksana intervensi melakukan wawancara dengan ibu untuk mengetahui positive reinforcer yang efektif bagi partisipan. Reinforcer akan diberikan apabila $A$ berhasil mencapai tahapan yang telah ditentukan.

a) Social reinforcement : berupa pujian diberikan setiap A berhasil mengerjakan satu tahap dalam memakai kemeja. Misalnya "Sip" (sambil mengacungkan jempol), "Oke" (sambil mengacungkan jempol), "A pintar!".

b) Consumable reinforcement : berupa makanan yang akan diberikan di akhir sesi setiap $A$ berhasil mencapai target pada minimal 3 dari 5 percobaan yang diberikan dalam satu sesi. Consumable reinforcer yang diberikan misalnya biskuit, sereal, dan minuman kesukaan $\mathrm{A}$.

Data observasi berdasarkan task analysis perilaku mengenakan kemeja berkancing dari sesi baseline, intervensi, dan follow-up dianalisis dengan metode visual insepection, yaitu dengan membandingkan hasil ketika tidak diberikan intervensi dan saat diberikan intervensi (Kazdin, 20 I3). Analisis data dilakukan dengan cara membandingkan data grafik penguasaan langkah perilaku mengenakan kemeja berkancing sebelum, saat, dan setelah intervensi dilaksanakan.

\section{Hasil}

Proses pelaksanaan intervensi modifikasi perilaku ini berlangsung selama 6 hari. Program dilaksanakan di rumah A setiap pagi hari selama 45 - 60 menit pada pukul 10.30-1 I.30. Selama intervensi, A menggunakan kemeja yang sama dalam setiap sesinya. Pada pelaksanaan intervensi ini, pelaksana intervensi bertugas sebagai agen pengubah perilaku, sedangkan ibu partisipan berperan sebagai observer dan melakukan percobaan terakhir di setiap sesi. Hal ini bertujuan agar ibu dapat memahami proses pelaksanaan intervensi yang telah dirancang.

Berikut ini merupakan grafik penguasaan kemampuan berpakaian A pada tahap baseline, intervensi, dan follow-up: 


\section{Gambar 2. \\ Perbandingan hasil baseline, intervensi, dan follow-up perilaku mengenakan kemeja berkancing}

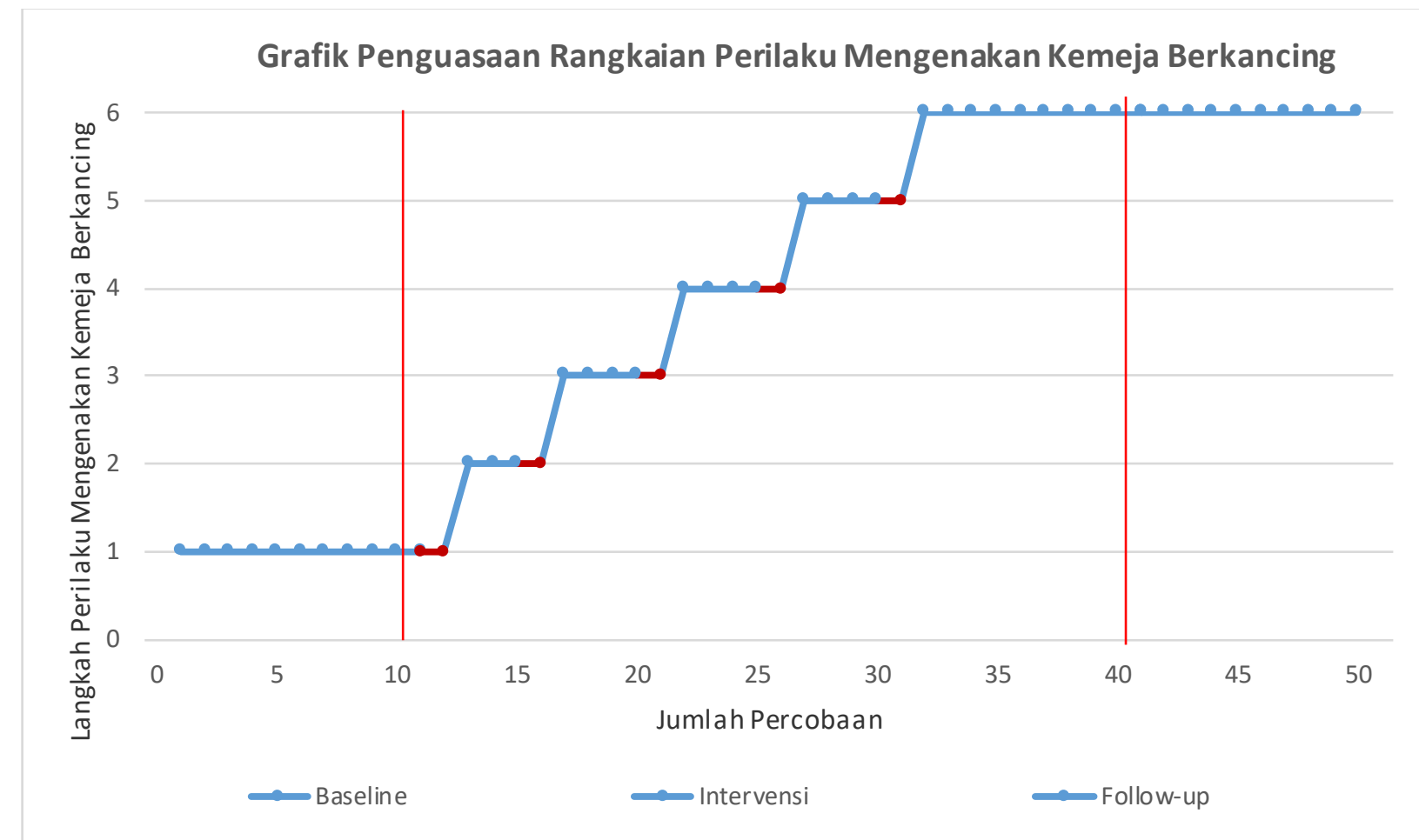

Keterangan:

Warna biru : anak berhasil melakukan langkah secara mandiri

Warna merah : anak gagal melaksanakan langkah yang diminta (masih memerlukan prompt fisik)

Grafik menunjukkan bahwa terdapat peningkatan kemampuan memakai kemeja yang dilakukan oleh A. Secara umum terlihat bahwa kemampuan penguasaan tahapan perilaku memakai kemeja pada $A$ menunjukkan adanya peningkatan dilihat dari percobaan I hingga percobaan ke 50 selama fase baseline, intervensi, hingga follow-up. Perbandingan hasil baseline, intervensi, dan follow upmenunjukkan bahwa $A$ yang pada awalnya hanya mampu menguasai I dari 6 tahapan perilaku memakai kemeja akhirnya dapat menguasai keseluruhan rangkaian perilaku memakai kemeja dengan tepat setelah menjalani sesi intervensi. Selain itu, grafik juga menunjukkan bahwa kemampuan $A$ tetap bertahan pada sesi follow up. Hal tersebut menunjukkan bahwa kemampuan memakai kemeja berkancing pada A mampu dikuasainya secara konsisten. Hasil intervensi ini juga menunjukkan bahwa $A$ sudah memahami konsep rangkaian perilaku memakai kemeja dengan tepat.

Pada percobaan pertama setiap sesi intervensi, A pada umumnya membutuhkan physical prompt I berupa arahan secara fisik untuk melakukan target perilaku. Misalnya, pada percobaan I tahap ke-I, A membutuhkan bantuan pelaksana intervensi secara fisik untuk melakukan langkah ke 2 (membentangkan kemeja). Begitupun pada percobaan I tahap ke-4, A membutuhkan bantuan pelaksana intervensi secara fisik untuk melakukan langkah ke-4 (memasukkan tangan ke lubang sebelah kiri). Pada percobaan ke- 2 hingga ke- 5 dalam setiap sesi, A pada umumnya berhasil mencapai target perilaku pada setiap sesi tanpa pemberian bantuan secara fisik. Setiap kali A kesulitan melakukan langkah terakhir dari target perilaku (mengancingkan baju), ia akan merengek dan meminta bantuan pelaksana intervensi.

Pada umumnya, A menunjukkan sikap kerja yang kooperatif selama program modifikasi berlangsung. Meskipun ia pernah menampilkan perilaku tidak bersemangat, ia tetap mau melaksanakan intervensi hingga selesai. A selalu melaksanakan ke-6 langkah hingga selesai. Bahkan saat sesi ke 5 A sudah 
dapat mengancingkan kemeja secara mandiri. A sempat menunjukkan sikap kerja kurang kooperatif pada saat diperhatikan oleh ibunya, seperti mengajak ibunya bercanda. Untuk mengatasi hal tersebut, peneliti hanya meminta ibu untuk hadir pada percobaan terakhir. Ibu juga diminta untuk mengabaikan tindakan A yang tidak sesuai dengan tugas dan memuji $A$ saat ia menjalankan instruksi dari pelaksana intervensi. Selain itu, kondisi ruangan yang sempit dan terdapat banyak barang-barang membuat $A$ mudah terdistraksi, misalnya tiba-tiba ia menunjuk foto neneknya yang ada di dinding untuk memberitahu pelaksana intervensi.

Dalam hal reinforcer, penggunaan bentuk social reinforcer dan consumable reinforcer pada program ini terbukti dapat meningkatkan dan mempertahankan perilaku memakai kemeja berkancing pada $A$. A terlihat senang dan bersemangat pada saat pelaksana intervensi memberikan ia pujian setiap kali berhasil melakukan suatu tahapan dalam rangkaian perilaku. A juga terlihat senang setiap kali menerima makanan yang diberikan di akhir sesi.

\section{Pembahasan}

Hasil intervensi menunjukan adanya perubahan perilaku mengenakan kemeja berkancing dari fase baseline hingga fase follow up. Pada saat fase baseline, A hanya mampu melakukan langkah pertama dalam tahapan mengenakan kemeja berkancing. Pada saat fase intervensi hingga follow up, A sudah mampu mengenakan kemeja berkancing secara mandiri.

Terdapat beberapa hal yang mempengaruhi keberhasilan intervensi. Pertama, kesesuaian teknikyang digunakan untuk melatih keterampilan mengenakan kemeja berkancing. Teknik forward chaining terbukti efektif dalam melatih keterampilan pada anak dengan intellectual disability (Mustikawati \& Kurnianingrum, 2018; Natasya \& Tirta, 2018). Teknik forward chaining yang digunakan dalam intervensi ini mengajarkan suatu rangkaian perilaku secara bertahap satu demi satu dimulai dari langkah yang paling mudah dilakukan (mengambil kemeja) hingga langkah akhir (mengancingkan kemeja) secara berurutan. Rangkaian disusun sesederhana mungkin agar memudahkan untuk dijalankan oleh anak. Akhmetzyanova (20I4) instruksi yang diberikan tahap demi tahap yang terstruktur penting untuk mengajarkan keterampilan bantu diri kepada anak dengan intellectual disability. Sejalan dengan hasil penelitian sebelumnya yang dilakukan oleh Jaslinder dan Hildayani (2019) bahwa teknik forward chaining efektif meningkatkan kemampuan memakai baju berkancing pada anak dengan intellectual disability taraf sedang.

Dalam teknik forward chaining, terdapat prompting dan positive reinforcement yang mendukung tercapainya tahapan-tahapan perilaku. Martin \& Pear (20I5) menyatakan bahwa pada beberapakasus, seperti anak dengan intellectual disability sebaiknya diberikan suatu model atau contoh seluruh rangkaian yang akan diajarkan sambil dijelaskan secara verbal pada setiap langkahnya. Pada sesi pertama, A ditunjukkan video dari youtube berisi seorang anak mengenakan kemeja bekancing. Pemberian prompt melalui video dikarenakan A senang menonton video Youtube. A juga terlihat sangat antusias saat video ditampilkan. Selain itu, pemberian physical, verbal, dan gestural prompting juga membantu dalam memunculkan rangkaian perilaku yang ditargetkan.

Dalam setiap tahapan intervensi forward chaining, pemberian positive reinforcement secara konsisten membantu tercapainya target perilaku anak. Reinforcement dapat meningkatkan motivasi pada anak untuk berupaya melakukan target perilaku dengan optimal. Miltenberger (20I2) menyatakan bahwa ketika perilaku diperkuat dengan reinforcement, maka perilaku tersebut lebih mungkin terjadi lagi di masa depan. Sebelum intervensi dilaksanakan, peneliti melakukan asesmen reinforcer menggunakan agar dapat memberikan reinforcer yang sesuai dengan minat anak. Dalam intervensi ini, peneliti menggunakan reinforcement berupa social reinforcer dan consumable reinforcement. Social reinforcement yang diberikan misalnya pujian dan pelukan. Consumable reinforcement yang diberikan berupa makanan kesukaan A misalnya biskuit dan minuman. 
Selanjutnya, penggunaan kemeja yang sama pada setiap sesi intervensi juga dapat mempengaruhi penguasaan anak dalam mengenakan kemeja berkancing, sehingga anak tidak perlu menyesuaikan diri kembali dan cenderung menghadapi suatu hal dengan tingkat kesulitan yang sama selama sesi dilaksanakan. Pelaksana intervensi juga mengantisipasi kebosanan yang mungkin akan dialami oleh anak selama menjalani sesi modifikasi perilaku. Terdapat jeda waktu untuk melakukan aktivitas yang disukai oleh A, misalnya kegiatan mewarnai.

Meskipun demikian, terdapat beberapa faktor yang menghambat intervensi, yaitu A cenderung bercanda saat diamati oleh ibunya. Misalnya ia mengatakan "mah-mah" sambil tertawa, atau terkadang mengedip-ngedipkan mata kepada ibunya. Pelaksana intervensi mengatasi perilaku dengan meminta ibu untuk hadir pada percobaan terakhir setiap sesi intervensi serta mengabaikan $A$ setiap kali ia menampilkan perilaku tersebut. Selain itu, A terkadang terdisraksi dengan hal-hal lain di luar intervensi. Karakteristik mudah terdistraksi merupakan salah satu yang umum dijumpai pada anak dengan intellectual disability (Djuric-Zdravkovic, Japundza-Milisavljevic, \& Macesic-Petrovic, 2010).A merupakan anak intellectual disability tingkat sedang, usia mentalnya setara dengan anak usia 3 tahun. Dengan kognitif yang terbatas tersebut mempengaruhi bagaimana proses belajar dan antensinya.

Hasil intervensi ini juga menunjukkan bahwa anak sudah memahami konsep rangkaian perilaku memakai kemeja dengan tepat. A mampu mempertahankan kemampuannya dalam mengenakan kemeja berkancing secara mandiri. Program intervensi ini dapat digeneralisasikan karena kemunculan perilaku A tidak bergantung pada pemberian reinforcement. Pada saat sesi follow-up, A sudah tidaklagi diberikan reinforcement berupa consumables (makanan) maupun social (pujian). Dengan demikian, perilaku A memakai kemeja berkancing tidak tergantung pada pemberian reinforcement.

\section{Kesimpulan}

Program intervensi dengan teknik forward chaining yang melibatkan prompting dan positive reinforcement efektif untuk melatih kemampuan mengenakan kemeja berkancing pada anak dengan intellectual disability taraf moderate/sedang. Terdapat perbedaan penguasaan kemampuan mengenakan kemeja berkancing yang signifikan antara sebelum dan setelah intervensi diberikan. Partisipan penelitian mampu mengenakan kemeja berkancing secara mandiri atau tanpa bantuan. Kemampuan partisipan awalnya hanya menguasai I dari 6 tahap menjadi menguasai keseluruhan rangkaian perilaku mengenakan kemeja berkancing.

Implikasi penelitian ini adalah bagi orang tua dan penelitian selanjutnya. Pertama, bagi orang tua, penelitian ini diharapkan dapat menambah wawasan bagi orang tua terlibat aktif dalam pemberian stimulasi anak-anak dengan intellectual disability, khususnya dalam hal keterampilan bantu diri. Keterampilan bantu diri sangat penting untuk dikuasai agar anak tidak bergantung kepada orang lain secara terus-menerus. Kedua, bagi penelitian selanjutnya dapat melakukan penelitian dengan metode forward chaining bersama teknik prompt dan positive reinforcement pada partisipan dengan intellectual disability dengan tingkat keparahan dan usia yang berbeda. Penelitian selanjutnya juga disarankan untuk mempersiapkan tempat pelaksanaan yang kondusif. Intervensi idealnya dilakukan di ruangan yang kondusif agar mencegah anak intellectual disability terdistraksi pada hal-hal yang ada di sekitarnya.

\section{REFERENSI}

Akhmetzyanova, A. I. (20I4). The development of self-care skills of children with severe mental retardation in the context of Lekoteka. World Applied Sciences Journal, 29, 724-727.

Doi: I0.5829/idosi.wasj.2014.29.06.13922 
American Psychiatric Association. (2013). Diagnostic and statistic manual of mental disorder DSM-5 (5th ed.). Washington, DC: Author.

Comer, J. \& Kendall, P. C. (20I3). The oxford handbook of research strategies for clinical psychology. New York: Oxford University Press.

Craig, F., Operto, F. F., De Giacomo, A., Margari, L., Frolli, A., Conson, M., Ivagnes, S., Monaco, M., \& Margari, F. (2016). Parenting stress among parents of children with Neurodevelopmental Disorders. Psychiatry Research, 242, I 2 I-129. Doi:10.1016/j.psychres.2016.05.016

Djuric-Zdravkovic, A., Japundza-Milisavljevic, M., \& Macesic-Petrovic, D. (2010). Attention in children with intellectual disabilities. Procedia Social and Behavioral Sciences, 5, I60I-1606. Doi:I0.1016/j.sbspro.2010.07.332

Hayton, J. A. (2016). Get Your Coat: Examining the Development of Independent Dressing Skills in Young Children with Visual Impairment in Comparison With Young Children With Down Syndrome and Typically Developing Children. (Thesis). UCL Institute of Education, London United Kingdom. Retrivedfrom https://discovery.ucl.ac.uk/id/eprint/I 54 I I 20/I/Jessica\%20Hayton\%20Thesis.pdf

Jaslinder \& Hildayani, R. (2019). Efektivitas teknik forward chaining pada kemampuan menggunakan kemeja pada anak dengan disabilitas intelektual. Jurnal Psikogenesis, 7(1), 18-27. Doi:1 0.24854/jps.v7il .874

Kazdin, A. E. (20I3). Behavior modification in applied settings (7th ed.). Illinois: Waveland Press.

Kumar, R. (20ll). Research methodology a step-by-step for beginners (3rd ed.). London: Sage Publications.

Lee, S. C., Muccio, B., \& Osborne, N. L. (2009). The effect of chaining techniques on dressing skills of children with moderate mental retardation: A single-subject design study. Journal of Occupational Therapy, Schools, \& Early Intervention, 2(3-4), 178-192. Doi: $10.1080 / 194$ I I 240903392590

Martin, G. \& Pear, J. (2015). Behavior modification: what it is and how to do it (9th ed.). New Jersey: Pearson, Prentice hall.

Marotz, L. R. \& Allen, K. E. (20I3). Developmental profiles: pre-birth throught adolescence (7th ed.). Belmont: Cengage Learning.

Matson, J. L., \& Hong, E. (2019). Self-help skills. In J. L. Matson (Ed.), Handbook of intellectual disabilities: Integrating theory, research and practice (pp. 763-773). Switzerland: Springer Nature.

Mays, N. M., \& Heflin, L. J. (20I I ). Increasing independence in self-care tasks for children with autism using self-operated auditory prompts. Research in Autism Spectrum Disorders, 5, I 35 I-I 357. Doi:10.1016/j.rasd.2011.01.017

Miltenberger, R. G. (20I2). Behavior modification principles and procedures (5th ed.). USA:Wadsworth Cengage Learning.

Mustikawati, A., Kurnianingrum, W. (2018). Penerapan forward chaining dalam meningkatkan kemampuan mandi secara mandiri Dada remaia dengan mild intellectual disability. Iurnal Muara IImu Sosial, Humaniora, dan Seni, 2(I), I 54-I 64. Doi: I 0.249 I 2/jmishumsen.v2il . 623

Natasya \& Tirta, S. (20I8). Penerapan forward chaining untuk meningkatkan kemampuan memakai baju pada anak penyandang disabilitas intelektual sedang. Iurnal Muara Ilmu Sosial, Humaniora, dan Seni, 2(I), 302-309. Doi:I0.249I2/imishumsen. v2il.1676

Sarafino. E. P. (20I2). Abblied behavior analysis: pinciples and procedures in behavior modification. Danvers, MA: John Wiley \& Sons. 